\title{
OBTAINING NEUTRON MATTER AND HYPERHEAVY NUCLEI: POSSIBLE QUANTUM-TECHNOLOGICAL INSTRUMENTAL APPROACHES
}

\author{
G.B. Ryazantsev ${ }^{1}$, V.I. Vysotskii ${ }^{2}$, G.K. Lavrenchenko ${ }^{3}$, S.S. Nedovesov ${ }^{2}$ \\ ${ }^{1}$ Lomonosov Moscow State University, Russia, ryazantsevgb@gmail.com \\ ${ }^{2}$ Taras Shevchenko National University of Kyiv, Ukraine, vivysotskii@gmail.com \\ ${ }^{3}$ LLC «Institute of Low Temperature Energy Technology», Odessa, Ukraine, \\ lavrenchenko.g.k@gmail.com
}

\begin{abstract}
Possible mechanisms of creation of both hyperheavy nuclei by electron-nuclear collapse and neutron matter by condensation of ultracold neutrons are discussed. The fundamental possibility of the existence of such objects was previously substantiated by A.B.Migdal, who suggested that the known set of proton-neutron nuclei with mass numbers from 0 to 300 and a maximum specific binding energy of about $8 \mathrm{MeV} /$ nucleon at $\mathrm{A} \approx 60$ corresponds to the first region, beyond which (starting from about the charge $\left.Z \approx\left(\hbar c / e^{2}\right)^{3 / 2} \approx 1600\right)$ there is
\end{abstract} an additional region describing a possible state of nuclear matter, stabilized by a pion condensate. In this region, the maximum specific energy corresponds to $\approx 15 \mathrm{MeV} /$ nucleon at $\mathrm{A} \approx 100000$. It is shown that neutron matter can be obtained under certain conditions, and its systematization can be realized as an addition to the Periodic Table. When solving such problems, it becomes quite real to study not only physical, but also chemical, and possibly engineering and technical properties. Analysis shows that the stability of neutron matter at the microlevel is ensured by the Tamm interaction and the Hund beta equilibrium. Such matter can be quite stable not only on the mega-level (neutron stars) due to gravitational interaction, as was a priori assumed earlier, but also on the scale of "ordinary" matter. The process of neutronization is possible not only with critical gravitational interaction, but also by other mechanisms (supercritical increase in the atomic number of elements due to electron-nuclear collapse and condensation of ultracold neutrons), which opens the way to the fundamental possibility of obtaining both neutron matter in laboratory conditions and superheavy nuclei.

Based on the works of Migdal, Tamm and Hund, the possibility of the existence of stable neutron matter (with $\mathrm{Z}$ $\gg 175, \mathrm{~N} \gg \mathrm{Z}, \mathrm{A}>10^{3}-10^{5}$ and a size of 200-300 femtometers and more) is argued at the microlevel, and not only at the mega-level, as is now considered in astrophysics.

A critical analysis of the well-established concept of the minimum possible mass of neutron stars is carried out. The following quantum technological approaches to the realization of UCN condensation are proposed: 1. Slow isothermal compression; 2. Refrigerator for dissolving helium-3 and helium-4; 3. Use of a conical concentrator for UCN focusing (Vysotskii cone); 4. Magnetic trap; 5. Additional UCN laser cooling. Neutron matter is considered as a potential cosmological candidate for dark matter. One should take into account the possibility of the formation of fragments of neutron matter as dark matter (neutral, femto-, pico- and nanoscale, the cooling of relics makes it difficult to detect them by now) already at the initial origin of the Universe, which is the dominant process. The observable part of the Universe is formed by the residual part of protons, and then by decayed single neutrons and unstable fragments of neutron matter (with $\mathrm{Z}>175, \mathrm{~N}>\mathrm{Z}$, but $\mathrm{A}<10^{3}-10^{5}$ ).

Key words: hyperheavy nuclei, neutron matter, electronnuclear collapse, condensation of ultracold neutrons, primary cosmogenic matter, dark matter.

АНОТАЦІЯ. Обговорюються можливі механізми створення як надважких ядр шляхом електронноядерного колапсу, так і нейтронної матерії шляхом конденсації ультрахолодних нейтронів. Принципову можливість існування таких об'єктів було раніше обгрунтовано А.Б.Мігдалом, який припустив, що відома множина протон-нейтронних ядр 3 масовими числами від 0 до 300 i максимальною питомою енергією зв'язку близько $8 \mathrm{MeB/нуклон} \mathrm{при} \mathrm{A} \approx 60$ відповідає першій області, за межами якої (починаючи приблизно з заряду Z>1600) існує додаткова область, що описує можливий стан ядерної матерії, стабілізованої піонним конденсатом. У цій галузі максимальна питома енергія відповідає $\approx 15$ $\mathrm{MeB/нуклон} \mathrm{при} \mathrm{A} \approx 100000$. Показано, що нейтронна матерія може бути отримана за певних умов, а іi систематизація може бути здійснена як додаток до Періодичної таблиці. При вирішенні таких завдань стає цілком реальним вивчення не тільки фізичних, але й хімічних, а, можливо, і інженерно-технічних властивостей. Аналіз показує, що стійкість нейтронної 
матерії на мікрорівні забезпечується таммовською взаємодією та бета-рівновагою Хунда. Така матерія може бути досить стійкою не тільки на мегарівні (нейтронні зірки) за рахунок гравітаційної взаємодії, як передбачалося раніше, але i в масштабах "звичайної" матерії. Процес нейтронізації можливий не тільки при критичній гравітаційній взаємодії, але й за іншими механізмами (надкритичне збільшення атомного номера елементів за рахунок електронноядерного колапсу та конденсації ультрахолодних нейтронів), що відкриває шлях до принципової можливості отримання як нейтронної матерії в лабораторних умовах, так і згоряння ядер.

На основі робіт Мігдала, Тамма та Хунда аргументується можливість існування стабільної нейтронної матерії (з Z $>175, \mathrm{~N}>\mathrm{Z}, \mathrm{A}>10^{3}-10^{5}$ та розміром 200-300 фемтометрів і більше) на мікрорівні, а не лише на мегарівні, як це зараз вважається в астрофізиці.

Проводиться критичний аналіз усталеної концепції мінімально можливої маси нейтронних зірок. Пропонуються такі квантово-технологічні підходи до реалізації конденсації UCN: 1. Повільний ізотермічний стиск; 2. Холодильник для розчинення гелію-3 та гелію-4; 3. використання конічного концентратора для фокусування UCN (конус Висоцького); 4. Магнітна пастка; 5. Додаткове лазерне охолодження UCN. Нейтронна матерія сприймається як потенційний космологічний кандидат у темну матерію. Слід враховувати можливість утворення фрагментів нейтронної матерії як темної матерії (нейтральної, фемто-, пико- і нанорозмірів, охолодження реліктів ускладнює їхнє виявлення до теперішнього часу) вже при початковому зародженні Всесвіту, що $\epsilon$ домінуючим процесом. Спостережувана частина Всесвіту утворена залишковою частиною протонів, а потім одиночними нейтронами, що розпалися, і нестабільними фрагментами нейтронної матерії (з Z>175, $\mathrm{N}>>\mathrm{Z}$, але $\mathrm{A}<10^{3}-10^{5}$ ).

Ключові слова: надважкі ядра, нейтронна матерія, електронно-ядерний колапс, конденсація ультрахолодних нейтронів, первинна космогенна матерія, темна матерія.

\section{Introduction}

Hyperheavy nuclei (Adamenko \& Vysotskii, 2004; 2005; 2006; 2007) as well as neutron matter (Ryazantsev et al., 2014; 2016; 2017; 2018), nowadays is a specific physical reality that requires the study of not only physical, but also chemical, and, possibly, in the near future, engineering and technical properties. Let us consider the possible mechanisms of the creation of hyperheavy nuclei by electron-nuclear collapse and neutron matter by condensation of ultracold neutrons (UCN). The fundamental possibility of creation of such objects was previously justified by A.B. Migdal, who suggested that the known set of proton-neutron nuclei with mass numbers from 0 to 300 and a maximum specific binding energy of about $8 \mathrm{MeV} /$ nucleon at $\mathrm{A} \approx 60$ corresponds to the first region, behind which (starting from the charge $Z \approx\left(\hbar c / e^{2}\right)^{3 / 2} \approx 1600$ ) there is still one additional area with a large value of the maximum binding energy at $\mathrm{A} \approx 100,000$, which describes a possible state of nuclear matter, stabilized by a pion condensate.

Neutron matter, or rather the corresponding element, begins (zero period) and ends (supercritical atoms) of the Periodic System of Chemical Elements (PS). Neutron matter is given stability already at the micro level Tamm interaction, and it is stable not only at the mega level (neutron stars) due to gravitational interaction, as is usually believed in astrophysics. Neutronization is possible not only due to gravitational interaction, but also through other mechanisms (supercritical increase in the atomic number of elements (Zel'dovich, 1971) and condensation of ultracold neutrons (Shapiro, 1976; Ignatovich, 1996). These circumstances show that there is a fundamental possibility of obtaining neutron matter in terrestrial conditions (Ryazantsev et al., 2014; 2016; 2017; 2018). Neutron matter is consistent with the original concept of the Periodic Law (PL) and PS, proposed by Dmitry Ivanovich Mendeleev (Mendeleev, 1934; Dobrotin et al., 1984).

From the standpoint of general chemistry, a neutron substance can be classified as chemically simple (that is, it cannot be decomposed into simpler substances by chemical means or reduced to allotropic modifications of already known substances), then the question inevitably arises about the corresponding element and its place in the PS. Proceeding from the logic of PL - (ordinal number electric charge) - the ordinal number of neutron matter in the PS will correspond to zero, which makes us recall and develop the ideas of Dmitry Ivanovich Mendeleev about the zero group and the period.

D.I. Mendeleev did not have time and opportunity to solve this problem, and his students and followers tried to forget this topic as "erroneous." Modern knowledge about neutron stars and neutron matter pers istently makes one recall his ideas about the elements disposed before hydrogen and assert the truth of his brilliant prediction, which more than 100 years ahead of the natural science of his time.

\section{Stability of hyperheavy nuclei and neutron matter}

In a neutron substance of sufficient size (more than a layer of complete absorption), an electron emitted during decay with its sufficient energy is captured by the remaining protons, which, in turn, are converted into neutrons, thereby maintaining the dynamic equilibrium of the system. In fact, this corresponds to both the theory of Igor Evgenievich Tamm (1975), which he put forward in his time (1934) to explain the mechanism of nuclear forces for ordinary nuclei, and the ideas of Frederick Hund (1936). It should be noted that the theory of I.E. Tamm was not satisfactory for ordinary atoms (but he himself valued his "unsuccessful" theory of nuclear forces more than the Nobel work on Cherenkov radiation and considered his best theoretical achievement), but it is consistent and can be realized for neutron matter of the 
corresponding scale (200-300 or more femtometers), giving it additional stability.

In strongly interacting systems, there are many virtual particles and all kinds of interactions that are allowed invariance considerations are realized. So, in our opinion, Igor Tamm's "primordial" theory of $\beta$-nuclear forces (lepton exchange between nucleons), and not only its modification by Hideki Yukawa ( $\pi$-exchange of nucleons), is still awaiting its recognition (because, besides the $\pi$ meson cloud, there are certainly other particles around each nucleon) and "dominates" in the neutron matter of the Universe, ensuring its stability and wide distribution.

The initial study of this problem was also given by Frederick Hund (1936) in the first microscopic description of the equation of state of nuclear matter in beta equilibrium in the article "Substance at very high pressures and temperatures", only if Tamm has virtual electrons, Hund realizes beta equilibrium completely real particles, but most importantly, both mechanisms contribute to the stability of supercritical $(Z>>175, N>$ $10^{3}-10^{5}$ ) nuclear matter, and in strongly interacting systems there is no fundamental difference between virtual and real particles.

It is the additional interaction due to nuclear $\beta$ - forces that gives stability to the neutron matter already at the micro-level, and not only at the macro-level due to the gravitational interaction, as it is now believed in astrophysics!

The possibility of the existence of a superdense neutron nucleus was also considered in the work of A.B. Migdal (1983) "Theory of finite Fermi systems and properties of atomic nuclei" in the section: "Application of the Theory of finite Fermi systems in nuclear physics". Migdal believed: "... neutron nuclei can be stable with respect to beta decay and fission, with $\mathrm{Z} \ll N$ and $N>10^{3}-10^{5}$. Such nuclei could be observed in cosmic rays in the form of large fragments." Migdal suggested looking for neutron nuclei in the form of exotic traces in photographic emulsions after exposure to cosmic rays.

The theories of Tamm, Hund and Migdal admit the stable existence of hyperheavy neutron nuclei at $\mathrm{Z} \gg 175$, $\mathrm{N}>10^{3}-10^{5}$ and sizes of 200-300 and more femtometers.

Nevertheless, it is widely believed that the minimum mass for the stable existence of a neutron object is 0.1 solar masses $\left(\mathrm{M}_{\odot}\right)$ (Potekhin, 2010) is believed that the equations of state used in this case are based on supposedly rich (?) Experimental material and therefore give a fairly accurate value for the minimum mass. The very fact of the existence of the minimum mass of a neutron star is justified by the fact that at low densities, neutrons, due to their susceptibility to beta decay, cannot be the predominant component of matter, and a high neutron density in them is provided only by gravitational interaction.

Most models of the neutron stars structure were based on the solution of the Tolman - Oppenheimer - Volkov equation (Potekhin, 2010). Currently, there are several dozen models, ranging from the so-called "soft" equations of state (derived from models in which, at densities of the order of nuclear, the average interaction energy corresponds to attraction) to rigid equations of state (obtained for models in which there is a repulsion). Since different models corresponding to different equations of state lead to a fairly wide range of parameters characterizing a neutron star, one might hope that an accurate determination of such parameters would make it possible to concretize the very equation of state of neutron matter, the very nature of internucleon interaction.

Unfortunately, until now it has not been possible to obtain reliable estimates of the main characteristics of neutron stars. Thus, the accuracy in determining the radius $\mathrm{R}$ is on average $50-100 \%$. To date, the equation of state has not been obtained in the framework of quantum chromodynamics. Thus, the minimum mass of a neutron star, considered to be equal to about $0.1 \mathrm{M}_{\odot}$ is obtained from insufficiently justified and incomplete equations with an error of up to $100 \%$ or more, as indicated in many papers on this topic. Despite this apparent uncertainty, such an estimate is widely replicated. For the first time, the limiting minimum possible mass of neutron stars appears in the work of Canuto (1975). In Canuto's study, neutron stars have a maximum mass of $1.75 \mathrm{M}_{\odot}$, above which collapse occurs; the minimum mass is $0.093 \mathrm{M}_{\odot}$, below which the star is unstable to free expansion to infinity (Pines, 1980). As already noted, most models of the structure of neutron stars are based on the solution of the Tolman-Oppenheimer-Volkov equation, i.e. the equation of hydrostatic equilibrium of a cold spherically symmetric star, in which the effects of general relativity are taken into account. In this case, the pressure $\mathrm{P}$ (r) and density should be connected by the equation of state, the definition of which contains the main difficulties, i.e., they are due to the fact that for the (fairly well known now) potential of inter-nucleon interaction one can construct various models consistent with "earthly" limitations, i.e., with data on scattering of free nucleons and on experimental determination of energy and equilibrium density of nuclear matter (Pines, 1980). However, when going beyond the known set of proton-neutron nuclei with mass numbers from 0 to 300 , the probability of new nuclear effects is high (Migdal, Tamm \& Hund).

Thus, based on the conclusions from the theories of Tamm, Hund, and Migdal, we can expect the stable existence of microscopic neutron objects $\left(Z>>175, N>10^{3}\right.$ $-10^{5}$ ) and neutron stars with a mass of less than $0.1 \mathrm{M}_{\odot}$. The author of the very concept of neutron stars, Fritz Zwicke (1958), wrote about the possibility of the existence of neutron objects of much smaller sizes (3-10 m) under certain conditions. He believed that further analysis of matter at nuclear density is important not only for our understanding of eruptions in stars, from ordinary star explosions to supernovae, but it also promises to radically change some of the current ideas on the formation of elements in the theory of the evolution of the Universe.

The question about the possibility of obtaining neutron matter under laboratory conditions on Earth is largely rhetorical. The point is that it is necessary to distinguish between two aspects: mononeutron (ultracold neutrons) and polineutron (similar to stellar cosmic) matter. As for the 
mononeutron matter, it has long been obtained in Earth conditions (Shapiro, 1968), although it is not stable (Ignatovich, 1996). It is interesting to note that on the one hand, a mononeutron substance, or rather an element corresponding to it, occupies a place in the PS before hydrogen, which corresponds to the element Coronium proposed by D.I. Mendeleev. On the other hand, the polyneutron matter closes the PS, thus, in the general case, the neutron matter both opens and also closes the PS. The question of obtaining polineutron matter is to be solved in the near future (Ryazantsev et al., 2014; 2016; 2017; 2018). The situation is now similar to that at the end of the 30 s of the last century, when a breakthrough was made in the mastery of nuclear energy, although many doubted the possibility of this.

\section{Obtaining hyperheavy nuclei by electron-nuclear collapse}

In the works of A.V. Migdal (1983) it was shown that for very heavy nuclei (starting from nuclei with a charge $Z \approx\left(\hbar c / e^{2}\right)^{3 / 2} \approx 1600$ ) there is a condensation of pions, which under this condition become real (not virtual) particles. Under this condition, a very significant rearrangement of the nuclear structure occurs, and the maximum specific binding energy is shifted from the range of standard parameters $\left(\mathrm{Z} \approx 60, \mathrm{E}_{\text {bond }} \approx 8 \mathrm{MeV} /\right.$ nucleon) to the range of mass numbers $A=100,000$, reaching the value of $\mathrm{E}_{\mathrm{bond}} \approx 15 \mathrm{MeV} /$ nucleon.

The main problem in the creation of such nuclei is the initial achievement of the $Z \approx 1600$ threshold, which corresponds to the conditional boundary (local minimum of the specific binding energy) between the "traditional" and "Migdal" regions of the mass numbers of nuclei. The scale of this problem is easy to imagine if we take into account the colossal efforts that are being made to create heavy nuclei with very moderate (on the scale of the Migdal model) charges $\mathrm{Z}=116-118$ due to the collision of lighter nuclei. It is quite obvious that such a "frontal" way of creation of hyperheavy nuclei due to the collision of lighter accelerated nuclei is absolutely unpromising.

In the articles (Adamenko and Vysotskii, 2004,2005,2007), a radically different method of "soft" (non-impact) step by step nuclear fusion of superheavy nuclei was proposed, which does not require the use of accelerators and special donor mother nuclei.

This method uses two processes:

a) Coulomb electron-nuclear collapse, based on the application of the nonlinear law of the Coulomb interaction of charges

$$
\mathrm{U}_{\text {eff }}=-\mathrm{Ze}^{2} / \mathrm{r}-\left(\mathrm{Ze}^{2} / \mathrm{r}\right)^{2} / 2 \mathrm{~m}_{\mathrm{e}} \mathrm{c}^{2},
$$

the most effective (maximally compressing the material environment) action of which is realized at a small distance $\mathrm{r}<\mathrm{Ze}^{2} / 2 \mathrm{~m}_{\mathrm{e}} \mathrm{c}^{2}$ or, respectively, at a very high density of electron-nuclear matter, compressed to the state of a degenerate relativistic electron gas;

b) the action of a strong axial shock wave providing the required compression ratio of the target at its front.
It is shown in (Adamenko \& Vysotskii, 2004; 2005; 2007), that when such a compression is performed, a self-controlled collapse of the electronic and nuclear components of the medium takes place, which sharply increases the degree of screening of the nuclear charge and provides the possibility of repeated (with a multiple increase in mass and charge) nuclear fusion with the participation (absorption) neighboring atoms and nuclei of the target. In addition, when these conditions are met, the process of protonization of nuclei becomes energetically favorable.

The combined action of these two processes leads to a continuous shift in the position of the maximum binding energy within the complete nuclear-electronic subsystems from the initial value $\mathrm{Z}=60$, typical for any matter under "standard" conditions, to values that can reach (and exceed) the critical value $Z \approx 1600$, upon reaching which the process of increasing the charge and mass of the nucleus will be provided mainly by the mechanism of pion condensation of Migdal.

Such a scheme was implemented under the leadership of S.V. Adamenko in Kiev at the «Proton-21» Laboratory $(2005,2007)$, in which nuclei with mass numbers in the range $A \approx 400-4000$ were created and registered in the course of experiments with the action of an axially symmetric electron beam on a needle target. On the basis of detailed mass spectrometric and spatial analysis of secondary light nuclei generated during rapid evolution in the vicinity of these hyperheavy nuclei, there are good reasons to believe that, upon entering the "ordinary" substance (storage screen located next to the target), these nuclei continued to grow, absorbing neighboring nuclei of the screen material (copper in conducted experiments) and "dumping" excess binding energy in the form of these secondary light nuclei.

We have also shown (Adamenko \& Vysotskii, 2006), that such a process, under certain (real) conditions, can occur on stars in the process of gravitational collapse, which can lead to the creation of proton-electron stars as an astrophysical alternative to neutron stars.

The main condition for the realization of such a scenario is an accelerated gravitational collapse, the duration of which should be significantly shorter than the duration of the stage of neutronization of nuclei. Analysis (Adamenko \& Vysotskii, 2006) shows that with successive compression of the stellar matter, these stages follow one after another; first neutronization and then protonization. If the compression in the process of gravitational collapse occurs rather slowly, then the compression process ends at the stage of formation of a neutron star. However, in the case of anomalously fast compression, only a small fraction of protons is converted to neutrons, and the subsequent compression will correspond to the stage of protonization of all nuclei with synchronous generation of electrons and antineutrinos. This stage begins from the moment when the main process of interaction of nuclei with electrons is the nonlinear Coulomb interaction, which corresponds to the concentration of electrons $\mathrm{N}_{\text {critical }}=\left(2 \mathrm{~m}_{\mathrm{e}} \mathrm{c}^{2} / \mathrm{Ze}^{2}\right)^{3}$ as part of a degenerate electron gas. 
Direct estimates have shown that for the formation of such anomalous stars, the final stage of gravitational collapse should be significantly less than $1 \mathrm{sec}$, which can be realized only with a very optimal ratio of the stellar parameters before its gravitational collaps.

If the compression process is long enough, the state of the star will stop at the stage of complete neutronization of all nuclei without "turning on" the mechanism of nonlinear Coulomb interaction, which is realized only at the subsequent compression and in the presence of a large concentration of nuclei that have not passed the neutronization procedure before this moment

\section{Obtaining of hyperheavy nuclei by neutron condensation}

It should be noted that Georgy Antonovich Gamov (1946) was the first to speak about the condensation of cold neutrons. This idea is rarely mentioned, which eventually found application in the theory of neutron stars. G.A. Gamow in the late 30 s of the last century showed that when a neutron gas is compressed, a new superdense state of matter arises. Gamow's main hypothesis: "We can anticipate that neutrons forming this comparatively cold cloud were gradually coagulating into larger and larger neutral complexes ...".

In further development, the theory of the initial cold universe was discarded and together with it the idea of neutron condensation was forgotten. However, is this true? Neutron condensation is possible not only at low temperatures (ultracold neutrons), but also at ultrahigh pressures at temperatures below critical.

Usually we on Earth deal with neutron radiation of various energies, but not with neutron matter. This was the case until 1968, when an experiment was carried out in the Laboratory of Neutron Physics under the leadership of Corresponding Member of the USSR Academy of Sciences Fedor Lvovich Shapiro (1976), in which the phenomenon of very slow neutron confinement in vessels, predicted by Academician Yakov Borisovich Zel'dovich (Ignatovich, 1996), was first observed. The behavior of neutrons trapped in evacuated vessels resembles the behavior of a highly rarefied gas in a vessel. Such neutrons are called ultracold (UCN). The confinement of UCN in vessels attracts researchers by the possibility (in comparison with a single flight of a neutron through the experimental volume) to observe this particle for a longer time in an experimental setup, which gives a significant increase in the sensitivity and accuracy of experiments on studying the interaction of neutrons with fields and matter.

For example, the use of UCN made it possible to significantly lower the limit of the existence of the electric dipole moment of the neutron, which is necessary to test the law of conservation of temporal parity; to more accurately measure the lifetime of a free neutron before $\beta$-decay. The most important feature of UCNs is that they behave not like radiation, but like matter, and you can work with them as with matter, similar to a rarefied inert gas. Moreover, you can study both physical and chemical properties. The physical properties are already being studied, but it seems that the question of UCN chemistry is not even raised, since by default it seems somehow obvious that they should be similar to inert gases. This seems to be true, but now we already well know that inert gases under certain conditions (in particular, in an excited state) can enter into chemical reactions and form, albeit not stable, chemical compounds of the excimer type. Could something like this happen with UCN? If we proceed from the fact that Chemistry is only the interaction of the electronic shells of atoms, as many believe, then a categorical negative answer follows. But, if chemistry is understood more broadly, in general, the ability of micro (nano, pico or even femto) objects to interact and form relatively stable compounds, then why not?

Of course, neutrons have no electric charge and no free electrons, so all ideas about possible classical chemical bonds (ionic, covalent, etc.) immediately disappear. But, neutrons have exactly a magnetic moment and possibly an electric dipole moment (the essential role of which is well known in chemistry). This can facilitate the formation of quasi-stable multi-neutron complexes.

Some aspects of this problem were considered in (Vysotskii, 2011) when analyzing and justifying the possibility of creating neutron-nuclear molecules whose structure is similar to atoms with an electron substituted for a neutron.

Another option may be associated with the interaction of UCNs with molecules of substances with an odd number of electrons, and an experiment to detect the products of this interaction is quite realistic (Ryazantsev et al., 2017) someone finds it difficult to go beyond the concepts of traditional chemistry, then we can call it the quasi-chemistry of UCN.

New UCN sources are being actively developed all over the world, some of them are based on the use of solid deuterium at a temperature of $4.5 \mathrm{~K}$ (LANL, USA; PSI, Switzerland), and others - on the accumulation of UCN in superfluid helium (KEK-RCNP-TRIUMF, Japan-Canada; ILL, France) (Serebrov et al., 2011). Similar work is being intensively carried out in Russia: the Neutron Laboratory at the Joint Institute for Nuclear Research (Dubna) and at the Petersburg Institute of Nuclear Physics (PNPI). In Gatchina, work is underway to create a high-intensity UCN source. With its help, they hope to obtain data that will provide answers to the most important questions of modern physics. The projected source will make it possible to obtain an ultracold neutron (UCN) flux with a density of $10^{4} \mathrm{~cm}^{-3}$, which is many times higher than the currently reached maximum densities (Serebrov et al., 2011). This task - obtaining intense UCN fluxes - is today considered one of the priorities in neutron physics. An ever increasing increase in the UCN density will inevitably lead to the formulation of the question of their possible condensation and the production of condensed neutron matter in laboratory conditions, similar to space.

Not so long ago, a decisive breakthrough was made into a new field: a radically new type of matter was created, the so-called Bose condensates of atoms. Are neutron condensates possible? Condensates, the density 
and strength of which will be comparable to the density and strength of atomic nuclei. In other words, how close are we today to the stage of creating cosmic neutron matter in the laboratory?

The 2001 Nobel Prize in Physics was awarded to researchers Eric A. Cornell, Wolfgang Ketterle and Carl E. Wieman (2003) for obtaining and studying the properties of the fifth state of matter, the Bose-Einstein condensate: they were able to obtain for the first time the Bose condensate. It was possible to do this with the help of the methods of supercooling of particles by laser beams and a magnetic field, developed not long before. The Bose condensate of atoms was obtained in a form convenient for research and laboratory analysis. Soon, methods were found for obtaining Bose condensates of particles of half-integer spin, fermions. In them, the particles are combined in pairs, then collecting in a Bose condensate. Neutrons are similar in many properties to the lightest atoms. For example, the mass of a neutron is practically equal to the mass of a hydrogen atom, the Bose condensate of which was obtained by Ketterle in 1997. But, unlike atomic Bose condensates, the natural compression of which during Bose condensation is impeded by their electron shells, nothing prevents the compression of a neutron Bose condensate. In such a condensate, the UCN gas - forms pairs with opposite spins, upon reaching the critical density and temperature, it will spontaneously shrink to almost nuclear density when nuclear forces come into play, forming a stable state condensed neutron matter. If in space a stable polineutron substance is formed at ultrahigh pressures, then on Earth it will be obtained at ultralow temperatures with a sufficient concentration of UCN, which sooner or later researchers will come to obtain.

The following quantum technological approaches to the implementation of UCN condensation are possible:

1. Slow isothermal compression;

2. Refrigerator for dissolving helium-3 and helium-4;

3. Use of a conical concentrator for UCN focusing (Vysotskii and Kuzmin, 1987);

4. Magnetic trap;

5. Additional UCN laser cooling.

\section{Neutron matter in cosmology and astrophysics}

The importance of neutron matter can hardly be overestimated in the astrophysics of neutron stars. It is now believed that all medium and heavy mass chemical elements almost appeared in the "thermonuclear reactors" of stars and supernovae. The Big Bang prepared only the fuel (a few of the lightest elements) for them. The lion's share came from hydrogen, which is still (and by a wide margin) the most abundant in the Universe. However, small amounts of helium, beryllium and lithium were formed at the same time. Theorists explained with good accuracy why they formed in one or another quantity. With one exception: current concentration of lithium in the Universe cannot be predicted. The isotope of lithium-7 is three times less than it turns out in theory, and lithium-6 is 300-500 times more. This discrepancy remains a real headache for cosmology: it is not possible to "fit" the Big Bang model to it, and some suitable explanations call into question the Big Bang itself.

In the theory of the Big Bang of a hot Universe, the formation of nucleons begins approximately from time $\mathrm{t}=$ $10^{-5} \mathrm{~s}$, temperature $\mathrm{T}=10^{12} \mathrm{~K}$ and particle energy $\mathrm{E}=0.1$ $\mathrm{GeV}$. Protons and neutrons are implied, but for some reason only protons are considered as active participants in possible fusion. Although, if we calculate the density of matter at this moment (Chernin, 1994), then it exceeds the density of a neutron star. That is, under these conditions the overwhelming majority of nucleons potentially could be in the form of neutrons since the conditions of neutronization are fulfilled.

It is more likely to expect the possibility of collective condensation of neutrons (for the most part, rather than sequential addition of individual neutrons, as Gamov and co-workers believed) upon reaching a critical temperature (which is an energetically more favorable process) than thermonuclear fusion from a minimum number of protons in those the same conditions. Fragmentary condensation of neutrons due to quantum-gravitational density fluctuations occurs with the release of additional energy, which enhances the formation of hyperheavy stable neutron nuclei, which are the source of non-relativistic dark matter (neutrality, femto-, pico- and nano-sizes, relic cooling to our time make it difficult detection - with $\mathrm{Z}>>$ $175, \mathrm{~N} \gg \mathrm{Z}$ and $\mathrm{N}>10^{3}-10^{5}$, stable dark matter $-\mathrm{SDM}$ ). The observable part of the Universe is formed from the residual part of protons and subsequently decayed single neutrons and unstable fragments of neutron matter (with Z> 175 , but $\mathrm{N}<10^{3}-10^{5}$, decaying dark matter - DDM).

Thus, it is necessary to consider the possibility of the formation of neutron matter fragments as part of dark matter (neutrality, femto-, pico-, and nano-size, relic cooling make them difficult to detect) already in the initial moments of the universe's birth, which is the initial dominant process in primary nucleosynthesis, rather than thermonuclear fusion from the initial small number of protons.

However, further, as it cools, the process proceeds according to the generally accepted scenario with thermonuclear fusion against the background of decay of an unstable component of neutron matter (Chudaykin et al., 2016; 2018).

\section{Conclusion}

Summing up a brief summary, it can be noted that hyperheavy nuclei and neutron matter in our time is a very specific physical reality, which urgently requires its rightful place in the PS and the study of not only physical, but also chemical, and possibly in the near future, and engineering properties. Neutron matter, or rather an element corresponding to it, begins (zero period) and ends (supercritical atoms) of the PS of elemen ts. Neutron matter is given stability already at the micro-level due to additional (Tamm, Hund, Migdal) interaction, and not only at the macro-level due to gravitational interaction, as is now believed in astrophysics. The possibility of 
polineutronization is shown not only due to gravitational interaction, but also by other mechanisms (supercritical increase in the ordinal number of elements and condensation of UCNs), thus, there is a fundamental possibility of obtaining neutron matter under terrestrial conditions (at $\mathrm{Z}>>175, \mathrm{~N}>10^{3}-10^{5}$ and size $200-300$ and more femtometers). Neutron substance is a necessary link connecting (throwing a bridge) from micro - to macro and mega World, from free neutron to neutron stars and Black holes. There is a high probability that such extremely concentrated matter represents thermodynamically and statistically the most stable state of matter as such. This substance can be thought of as a multitude of tightly packed neutrons, with scattered residual protons and electrons among them.

It is necessary to take into account the possibility of the formation of fragments of neutron matter in the form of dark matter (neutrality, femto-, pico- and nano-sizes, relic cooling complicate their detection) already at the initial moments of the birth of the Universe, in which the neutronization process predominates, and not thermonuclear fusion from the initial insignificant amount of protons. Further, as it cools, the process proceeds according to the generally accepted scenario. Neutron matter consistently fits into the initial concept of PL and PS put forward by Dmitry Ivanovich Mendeleev, whose 150th anniversary we have recently celebrated (Mendeleev, 1934; Dobrotin et al., 1984).

\section{References}

Adamenko S.V., Vysotskii V.I.: 2004, Found. Physics. Lett., 17, No.3, 203.

Adamenko S.V., Vysotskii V.I.: 2004, Found. Physics, 34, No.11, 1801.

Adamenko S.V., Vysotskii V.I.: 2006, Found. Physics. Lett., 19, No.1, 21.

Adamenko S.V., Vysotskii V.I.: 2007, In Book: Controlled Nucleosynthesis. Breakthroughs in Experiment and Theory /Eds.: S.V.Adamenko, F.Selleri, A.van der Merwe, Series: Fundamental theories in Physics, 156, Springer, 363.

Adamenko S.V., Vysotskii V.I.: 2007, Ibid, 415.

Adamenko S.V., Vysotskii V.I.: 2007, Ibid, 401.

Adamenko S.V., Vysotskii V.I.: 2005, J. Surface Invest. Xray, Synchrotron and Neutron Techn., №4, 30 (In Russian).

Canuto V.: 1975, Ann. Rev. Astr. Ap., 13, 335.

Chernin A.D.: 1994, UFN, 164, №8, 889 (in Russian).

Chudaykin A., Gorbunov D., Tkachev I.: 2016, Phys. Rev., D 94, 023528.
Chudaykin A., Gorbunov D., Tkachev I.: 2018, Phys. Rev., D 97, 083508.

Dobrotin R.B., Karpilo N.G., Kerova L.S., Trifonov D.N.: 1984, Chronicle of the life and work of D.I. Mendeleev Ed. A.V. Storonkin, L.: Nauka (in Russian).

Gamow G.: 1946, Phys. Rev., 70, 572.

Hund F.: 1936, Ergebnisse der exakten Naturwissenschaften, 15, 189.

Ignatovich V.K.: 1996, UFN, 166, №3, 303/

Cornell E.A., Wieman C.E.: 2003, UFN, 173, №12, 1320

Mendeleev D.I.: 1934, Periodic Law. Works. L.-M., v. 2, Eds.: A.N.Bach, B.N.Vyropaeva, I.A.Kablukova, L.: GKhTI, 520 (in Russian).

Mendeleev D.I.: 1991, It is impossible to foresee the boundaries of knowledge. /Works. Ed. Yu.I. Soloviev, M., (in Russian).

Migdal A.B.: 1983, In Book: Theory of finite Fermi systems and properties of atomic nuclei, M., Nauka, 54 (in Russian).

Pines D.: 1980, UFN, 131, №3, 479.

Potekhin A. Yu.: 2010, UFN, 180, №12, 1279.

Ryazantsev G.B., Lavrenchenko G.K., Beckman I.N., Buntseva I.M., Nedovesov S.S.: 2018, Odessa Astron. Publ., 31, 33.

Ryazantsev G.B., Lavrenchenko G.K., Beckman I.N., Buntseva I.M., Nedovesov S.S.: 2019, ISINN-26, 26th Intern. Sem. Interact. Neutr. Nuclei, Dubna, JINR, Russia, 37.

Ryazantsev G.B., Lavrenchenko G.K.: 2014, Techn. Gases, №1, 3 (in Russian).

Ryazantsev G.B., Lavrenchenko G.K.: 2016, Techn. Gases, №4, 41 (in Russian).

Ryazantsev G.B.: 2016, Nauka i Zhizn’, № 2, 76 (in Russian).

Ryazantsev G.B., Lavrenchenko G.K., Beckman I.N., Khaskov M.A.: 2017, ISINN-24, 24th Intern. Sem. Interact. Neutr. Nuclei, Dubna, JINR, Russia, 65.

Ryazantsev G.B., Lavrenchenko G.K., Beckman I.N.: 2018, 18-th Gamow Summer School, Odessa, Ukraine, Abstracts, 15.

Serebrov A.P, Boldarev S.T., Erykalov A.N.: 2011, Physics Proc., 17, 251.

Shapiro F.L.: 1976, Neutron Research. Works. 2, M.: Science, 348 (in Russian).

Tamm I.E.: 1975, Theory of nuclear forces and atomic nucleus. Works, 1, M.: Science, 283 (in Russian).

Vysotskii V.I., Vysotskyy M.V.: 2011, J. Surface Invest. Xray, Synchrotron Neutron Techn., 5, №2, 330.

Vysotsky V.I., Kuzmin R.N.: 1987, Method of forming a pulsed neutron flux. Patent. No. 1346031.

Zeldovich Ya.B., Popov V.S.: 1971, UFN, 105, 403.

Zwicky F.: 1958, PASP, 70, 506. 